\title{
AC 2007-1771: MENTORING NEW FACULTY: HOW MUCH, HOW OFTEN, AND HOW?
}

\section{Andrew Jackson, East Carolina University}

Dr. Andrew E. Jackson is currently Professor and Chair of the Department of Technology Systems in the College of Technology and Computer Science at East Carolina University. He has over thirty five years of academic and industrial experience related to systems design, systems integration, quality, human factors, and distance education. Dr. Jackson has taught numerous courses in Face-to-face, blended, on-line and in distance learning environments. His research and publication interests include: systems design, human factors, ergonomics, systems safety, web-based learning, transportation, logistics, and aviation infrastructure issues.

\section{Robert Chin, East Carolina University}

Robert A. Chin is a Professor in the Department of Technology Systems, College of Technology and Computer Science at East Carolina University, where he's taught since 1986. In addition, he is a full member of the East Carolina University and Indiana State University graduate faculties.

Dr. Chin received his Ph.D. from the University of Maryland, College Park; MAE from Ball State University; BA from the University of Northern Colorado, and AAS from the Community College of the Air Force. Before joining the ECU faculty, he was on the College of Education faculty at the University of Maryland, College Park. Dr. Chin is an active member of ASEE. He has presented numerous papers at annual conferences, FIE, mid-year conferences/ meetings, and Southeastern Section meetings. He has had numerous journal articles published including several in the Engineering Design Graphics Journal. He has served as the ASEE's Engineering Design Graphics Division's annual and mid-year conference/meeting program chair, and he is presently review board member for several journals including the EDGJ. Chin has been a program chair for the Southeastern Section Meeting and has served as the Engineering Design Graphics Division's Vice-Chair and Chair and as the Instructional Unit's Secretary, Vice-Chair, and Chair.

\section{Charles Coddington, East Carolina University}

Dr. Charles E. Coddington is a professor in the Department of Technology Systems at East Carolina University where he teaches graduate courses in statistical applications and research methods. Dr. Coddington has extensive administrative and consulting experience in addition to his classroom expertise.

Dr. Coddington received his Ph.D. in Industrial Education with minors in Sociology and Quantitative Measurement, a M.Ed. in Industrial Education from the California University of Pennsylvania and the Pennsylvania State University and a B.S. in Industrial Education from the California University of Pennsylvania.

Dr. Coddington is the Technology Systems Department representative on the Faculty Senate at East Carolina University where he serves in leadership positions with in the university, the college, and the department.

\section{Paul Petersen, East Carolina University}

Dr. Paul F. Petersen is a professor of technology at East Carolina University's College of Technology and Computer Science where he is Assistant Department Chair and Director of Graduate Studies. He is Professor Emeritus from Cleveland State University's Fenn College of Engineering and has authored numerous articles and presentations over his 35 years in higher education. Dr. Petersen holds a Ph.D. in Industrial Engineering from Clemson University, an M.B.A. from Clemson-Furman University, and a BBA from Southern Methodist University. 


\section{Fonooni Hamid, East Carolina University}

Dr. Hamid Fonooni is currently an Associate Professor in the Department of Technology Systems, Master of Science Occupational Safety Program of the East Carolina University, Greenville, NC. Prior to joining ECU, during the past 12 years, Fonooni was an Associate Professor in the Department of Mechanical and Industrial Engineering, Master of Environmental Health and Safety Program of the University of Minnesota Duluth. He has started his involvement with ergonomics as a researcher as well as a practitioner since 1985. He has worked as a Senior Ergonomist for the Ohio Division of Safety and Hygiene in Toledo, Ohio for approximately seven years. He also has served as an Adjunct Professor at the Medical College of Ohio 1991-95, University of Toledo 1989-95, and University of Cincinnati 1985-90. Fonooni also served as an Associate Research Professor in the Master of Industrial Hygiene Program, School of Public Health of the San Diego State University in 1999-2000. Dr. Fonooni is an active member of American Society of Safety Engineer. He is currently the Assistant Administrator of the Academic Practice Specialty and serves on Educational Standards Committee as well as Chairing the Student Task Force of the ASSE. He has published and presented numerous articles, book chapters, papers, and reports related to occupational ergonomics.

Dr. Fonooni received his Ph.D. in Mechanical and Industrial Engineering from the University of Cincinnati in 1992, Masters of Science in Mechanical Engineering from the University of Cincinnati in 1982, and Bachelor of Science in Mechanical Engineering Technology from Indiana State University in 1980. He is also a Board-Certified Professional Ergonomist (CPE). 


\section{Mentoring New Faculty: How Much, How Often, and How?}

\section{Abstract}

The Department of Technology Systems (TSYS) at East Carolina University has implemented a new faculty mentoring process to enable junior faculty members to learn from senior faculty members as they prepare for a career in academia. Five tenured professors and associate professors in the TSYS department have recently established a new process to mentor faculty members within the department who have begun not yet completed their initial tenure process at a major university. This process includes a series of workshops regarding academic performance expectations during the early stages of an academic career. Our commitment to new faculty takes on several related, yet distinct features. Examples of these initiatives include: 1) reduced workloads for new faculty for the first two years to enable them to generate individual and collaborative research activities, funded grants, and publications, 2) periodic university-wide training to learn policies and procedures that affect day-to-day activities on a college campus, 3 ) periodic workshops hosted by senior faculty mentors, and 4) one-on-one discussions between senior faculty members and junior faculty members to encourage candid dialogue between professional colleagues. Another feature of the mentorship philosophy is a proposal to the dean of the college to offer newly hired faculty a contractual start date of July $1^{\text {st }}$ each year instead of starting their contract one week prior to the start of fall classes, normally in late August. This additional period of time will be used to train new faculty in essential policies and procedures, to complete a variety of administrative tasks on campus, to get a head start on preparing for classes in the fall, and cleaning up those supplemental tasks that accompany every move to a new location. The goal of this early commitment to new faculty is to reduce the stress associated with preparing for a new course, in a new environment, with a new set of operating procedures. This will also enable the mentorship team to begin the tenure preparation process under a more relaxed and effective environment. This paper will provide specific details of this new mentorship program and its effectiveness thus far.

Introduction

Originally established in 1996 and presently administered by Dr. Dorothy Howse Clayton, the primary mission of East Carolina University's (ECU's) “...Center for Faculty Development is to provide faculty members with resources and services that foster and support their efforts to create effective teaching and learning environments". 1 The Center (a) serves as one of the many sources of resources and materials appropriate for the common components of the tenure and promotion process, (b) helps facilitate the annual university-wide teaching awards program, (c) helps facilitate the tenure track probationary term faculty's mandatory classroom observation, (d) facilitates the conduct group sessions, (e) conducts workshops on constructing teaching portfolios, and (f) facilitates the development of research skills and access to research resources. Among the group sessions the Center facilitates is New Faculty Mentoring, a series of group meetings intended to familiarize new ECU faculty members with the institution's procedures and requirements and to facilitate professional development among interested colleagues. In addition to the New Faculty Mentoring program, ECU offers at least ten other faculty mentoring programs according to ECU's Faculty Welfare Committee. ${ }^{2}$ Furthermore, according to the Faculty Welfare Committee, ${ }^{2}$ of the two hundred and sixty-seven respondents 
to a online/ mail?? survey, almost fifty-two percent $(n=138)$ of the respondents reported that they participated in a faculty mentoring program at ECU. Seventy-two were mentees, fifty-nine served as mentors, and twenty-nine participated as both a mentee and a mentor. Ninety-three of the respondents reported that their faculty mentoring program was an informal faculty mentoring program while twenty-six participated in a formal faculty mentoring program. Forty-two respondents participated in formal and informal programs. With respect to the effectiveness of the mentoring programs, (a) 55.5\% of the mentees either rated their mentoring programs as "effective" or "very effective", (b) $16.7 \%$ of the mentees were undecided about the effectiveness of these programs, and (c) $27.8 \%$ ) of the mentees rated these mentoring programs as "ineffective" or "very ineffective." Among the mentors, (a) 55\% either rated their mentoring programs as "effective" or "very effective", $29.2 \%$ were undecided about the effectiveness of these programs, and (c) $15.7 \%$ of these respondents rated these mentoring programs as "ineffective" or "very ineffective." Over sixty percent of these respondents $(60.4 \%)$ received benefits from this faculty mentoring program and almost sixty percent of these respondents $(58.5 \%)$ said that they would participate in a faculty mentoring program in the future.

\section{Background}

At the beginning of the 2004-05 academic year, the East Carolina University Faculty Welfare Committee (FWC) was charged with reviewing and evaluating current faculty mentoring practices at ECU. This charge was in response to a concern on the part of the Faculty Senate that "...good colleagues have been given less guidance than they deserved"3 and that "...the energy and aspirations upon which our university is built are squandered as faculty attempt to move forward in their scholarly careers". 4

In partial response to their charge, the FWC conducted an investigation of existing faculty mentoring practices at ECU and solicited comments from the faculty. In response to their findings, the FWC formulate five initiatives. Their plan includes: (a) compiling a detailed list of mentoring practices at ECU, (b) determining whether there are differences between the faculty and university administrators in how faculty mentoring is perceived, (c) evaluating outside-of-ECU mentoring programs and whether individual ECU units recognize effective mentoring practices through concrete and tangible incentives, (d) investigating the nature of the formality of mentoring programs, and while mentoring is a form of faculty development and quite often associate with the professional development of new faculty members, (e) examining the professional development of ALL faculty members. ${ }^{5}$

While not in direct conjunction with work done by the FWC, but rather in response to a perceived need, the Department of Technology Systems (TSYS) at ECU has implemented an innovative faculty mentoring process that enables junior faculty members to learn from senior faculty members and prepare for careers in academia on a more formal basis. The department, however, will monitor the work done by the FWC and incorporate these findings. This paper provides specific details of this innovative mentorship program and its effectiveness. It discusses the (a) current procedures and policies for mentorship process at ECU-faculty manual, code, faculty senate, etc; (b) mentorship procedures used at other institutions-peers and others; (c) current faculty orientation process including first Personnel Action Dossier (PAD) delivery \& 
first-year training process, and (d) plans for future mentorship processes in the TSYS department.

Current Policies and Procedures for Mentorship Process at ECU

In Greek mythology, Mentor (sometimes Mentês) was the son of Alcumus and, in his old age, a friend of Odysseus. When Odysseus left for the Trojan War he placed Mentor in charge of his son, Telemachus, and of his palace. ${ }^{6}$ The academy utilizes this as the source of the modern use of the word mentor which implies: a trusted friend, counselor or teacher, usually a more experienced person.

The Center for Faculty Development, which was recently renamed the "Center for Faculty Excellence"; has been the center piece of the university's efforts for the mentorship of faculty. The role of the Center, through the use university resources, is to empower faculty with the knowledge to create an effective learning environment within their content area, as well as to provide the methodologies for a successful transition through the tripartite areas associated with the promotion and tenure process. ${ }^{7}$

The recent 2004-05 Faculty Welfare Committee Report on faculty development and mentoring examined the individuals impacted by the process. We commend the committee on their effort and for an excellent report. The university's commitment to mentorship of junior faculty is not only essential but evident by way of this report. Although significant resources and talent has been placed with the Center for Faculty Excellence to assist the individual faculty members, Colleges, Schools, and Departments, we eschew the notion that there is one model for mentorship across the university. ${ }^{8}$

The current ECU Faculty Manual, which guides administrators and faculty with respect to all aspect of university life, does not contain formal guidelines for faculty mentorship. It has no guide for the individual faculty or for the colleges and/or schools nor has the Faculty Senate proposed such a document. ${ }^{9}$ However, the Faculty Manual does contain extensive criteria with respect to promotion, tenure and the rights and responsibilities of faculty. It should be noted that every College and/or code unit at ECU has implemented procedures for mentorship of new faculty established by the individual units. ${ }^{10}$

The following are observed areas of emphasis addressed within the mentorship initiatives of the individual code units at ECU: (a) mechanisms to provide individual recognition and encouragement; (b) advice on appropriate balancing of teaching, research/creative activities and internal and external service responsibilities; (c) establishing individuals or groups to provide constructive criticism and informal feedback; (d) advice on scholarship/teaching; (e) insights into the informal and formal culture of the Department, College, University, and Faculty; and (f) providing information concerning the formal and informal rules for advancement. Areas needing improvement or seemingly missing as a part of the mentorship initiatives include but are not limited to the following: formal procedures for providing mentorship or a formal mentoring program linking university and departmental resources (human and material); the roles and/or responsibilities of the department chair, the mentor and the new faculty member; established Best Practices for mentoring or established Qualities of a 
Good Mentor; mentorship short and long term goals; mentorship training; and a continuous improvement feedback process. ${ }^{11}$

The Faculty Manual is clear on the roles and responsibilities of the Unit Administrator, the Department Chair, in some smaller units this may be the Dean or Associate Dean, therefore we recognize that the Chair retains the responsibility of reviewing the performance of each faculty member annually and providing candid feedback to all faculty including the junior faculty members with respect to their performance. The activities of mentorship however structured or not must work in tandem with the existing administrative structure to be successful.

Through recent conversations with the ECU Faculty Senate Chair, Dr. Mark Taggart, the faculty senate will commence work during spring 2007 through the following committees: Faculty Welfare, Faculty Recruitment and Retention and the University Code to create a joint initiative to bring about a formal mentoring policy and support for its implementation throughout the university. The Department of Technology Systems' initiative was not directly connected to the Faculty Senate research or the aforementioned activities but rather from a rapid expansion of faculty hires and the need to better assist the growing numbers of new faculty with the comprehension of the university culture and the demands which are innate to the environment within the academy.

\section{Mentoring Experience}

After serving in academia for several years, one gets to see a variety of mentorship programs to support new faculty in the department. Some of them are fresh out of graduate school and others are more experienced faculty who have some level of experience in navigating the political and professional minefields we call the tenure track. When we think of mentoring, our focus generally goes toward the new graduate who is fresh from receiving their doctorate. We tend to forget about our faculty colleagues who have recently changed positions and are starting the process anew at another institution. It must be noted that each institution has its own set of processes, expectations, personalities, and regulations that make each tenure process quite different from one institution to the next. These senior faculty members should also be included in the mentoring process. As we see it, there are four areas of mentoring: (a) the initial immersion into the Department, College, and University, and the three traditional areas of tenure: (b) teaching, (c) research and creative activity, and (d) service. All four areas should be addressed in any effective mentoring program. The initial immersion into a new program is a critical step for both groups of faculty - experienced and novice. Most schools tend to bring new faculty on-board a few days prior to the start of the semester, which typically, does not allow enough time for the faculty member to become acquainted with the school, the community, and colleagues and peers. This is generally justified as a budgetary issue, but this justification maybe a false economy and counterproductive, since this hiring process is considered to be a sevenyear to a lifetime commitment for both the college and the faculty member.

During this typical one week timeframe, newly-hired faculty members must settle into the new geographical area, take care of family obligations, in addition to the basic tasks of establishing their office. This equates to finding a suitable place to live, moving and establishing 
residency in the new location including acquiring new drivers licenses and vehicle registrations, and locating schools, churches, grocery stores, and shopping areas, along with preparing to teach two to four new courses. In addition, the faculty members must acquaint themselves with the campus, complete the hiring paperwork, apply for employee benefits, establish retirement programs (a life-long impact issue for which they typically have 30 days or less to select). This is a critical and stressful time for new faculty members. An effective mentoring system should start early enough in the cycle, to make the transition a smooth as possible. Making sure there is a mentor assigned before the new faculty member arrives is a critical first step.

Once the new faculty member has committed to join the new program, the most experienced and best qualified faculty in the unit must take on a mentoring role, and do so willingly. In many instances, the initial mentors should be junior faculty members who have been hired within the previous year or two. There are two reasons for taking this position. First, they have just been through the process themselves and are probably still familiar with the problems, shortcuts, and key people within the system who can ease the transition process. Second, they are probably closer in age to the new faculty and will generally have more in common, both socially and professionally, than more senior faculty members.

Mentoring for tenure and promotion, which most leaders in academia consider the reason for all professional development in a university system, is secondary at this moment in time to getting the faculty off to a good start. Once the new faculty member has settled in to their new role, then the mentoring for promotion and tenure should take precedent. Professional development mentoring should be a peer process allowing the mentor and the new faculty find each other. For mentoring to be successful, there must be a common ground to form the basis of a successful long-term professional relationship. This may be research interests, previous school affiliations, recreational activities, geographic background, travel interests, and/or social activities. The key factor is that the mentor must have a strong desire to see this person succeed. The challenge is to find this common ground that will make the process a success. The mentor in this case needs to be a faculty member who has been through the process and preferably has served on the promotion and tenure committee. Someone with this type of experience has the knowledge to effectively and accurately advise the new faculty and guide them through the requirements for tenure and promotion within the new system. They should also be in a position to make recommendations to the mentee that will be accepted and integrated into annual action plans from the very early stages of development.

The authors of this paper have seen a number of outstanding mentors at different phases of their careers. Many of these mentors have been focused on research productivity while others focus on the holistic development of the individual and see promotion and tenure as a tools to recognize those individuals who prove themselves to be competent in the three major areas of the academy - reaching, research/creative activity, and service, Most successful mentors have several characteristics in common:

1. Your success is important to them - not what you could do to further their career

2. They hold high ethical standards themselves and expect no less from you

3. They have a proven history of teaching, research, and funded grants 
Conclusions

Mentoring programs run the gambit from being no help in some cases to the other extreme of smothering new faculty and overwhelming them with sage advice and historical trivia. In intuitions were there is no mentoring, faculty members often flounder for a period of time and if they "have what it takes," they will do well and flourish on their own imitative. In many organizations this is done intentionally. This attitude is typically based on the old guard concept of "that is what I had to do to get through, so let them sink or swim." This attitude is counterproductive and our collective attitudes need to be adjusted to believe that every faculty we hire is going to make it through the tenure and promotion process in the allotted time. In academia, we can no longer treat faculty at a disposable resource. When we hire faculty, we hire them with the understanding that they are capable of attaining tenure. One way to help insure the success of faculty in the tenure process is to institute a peer mentoring process.

One major pitfall any mentoring program must avoid is for mentors to control new faculty to the point that the new faculty becomes the research or teaching slave of the mentor. There are faculty members, who will be referred to as predator faculty, who are looking for graduate students and junior faculty as a resource to help them conduct their research or do their teaching. We have all seen or heard of situations were graduate students take years to finish their degree programs because of a hyper-controlling faculty member. The administration and the senior faculty in the academic unit must be cognizant of these individual personality issues and must guard against placing these self-centered individuals into a position of influence over the next generation of faculty. Mentoring poor behavior is a recipe for developing future generations of self-centered faculty members who are only in it for themselves. There are also cases of junior faculty who get into similar, destructive relationships and they are often afraid of reprisals if they say or report anything regarding their treatment at the hands of their "mentor." Oftentimes, they wind up not getting tenure because they have not done sufficient high quality work in the areas necessary to be awarded tenure.

Mentorship Procedures Used at Other Institutions

Twenty four universities and colleges mentoring programs have been reviewed to determine the commonality and traits that have been most effective in launching and maintaining a new faculty mentoring program. Out of the twenty four universities and colleges, ten possess a well defined process for the new faculty mentoring. Most of the published documents are intended to provide a guideline to the mentors as well as mentees (new faculty). While the documents do not guarantee the job satisfaction for the new faculty, they are intend to offer support, encouragement, and useful information.

Some universities, such as Auburn University, have taken this process more seriously than others and through an Ad Hoc committee have prepared a final report to the university senate. Auburn University Ad Hoc Committee on Junior Faculty has initiated their process by distributing articles for their own educational purposes. The next step for the Auburn University Ad Hoc committee was to conduct a Needs Assessment Survey Responses from faculty with less than 5 years of teaching experience at AU. According to the responses, the AD Hoc Committee developed their final report and recommendations. 
"The University of Guelph is renowned in Canada and around the world as a researchintensive and learner-centered institution and for its commitment to open learning, internationalism and collaboration." Gilian Heather MacPherson of the University of Guelph, with the help of other colleagues, has developed a document on "New Faculty Mentoring, Best Practices and Recommendations". Even though this document is considered to be "a work in progress" it appears to have some valuable and to the point recommendations for all levels of organization.

In a document called Mentoring Program Guidelines for New Faculty the Austin Peay State University New Faculty Mentoring Committee has prepared has documented clear guidelines for the administration as well as the faculty mentors and mentees.

Northern Illinois University in a recently updated document (2006) presented the essence of New Faculty mentoring process including roles and responsibilities of the mentors as well as the mentees. The document includes The 10 Commandments of Mentoring.

Washington State University developed a comprehensive document on Faculty Mentoring Guidelines. In this document, responsibilities and roles of involved parties, including the mentors, mentee, and the department chair are spelled out. This document appears to be the result of a comprehensive literature review on this topic.

In January 2001, the Mentoring Program for new faculty was piloted at Benedictine University located in Lisle, Illinois. As result of this pilot plan, a well prepared Handbook and Guidelines was published. In this document, qualifications and responsibilities of the mentors, as well as roles and responsibilities of the mentees is discussed. Also, this Handbook recommends a letter of intention from the mentor faculty must be filed with the office of provost before the mentoring process stars.

Many universities and colleges have made serious efforts to address the new faculty mentoring issue. Some universities have developed valuable handbooks and guidelines. By reviewing the available guidelines and literature regarding faculty mentoring, seemly most institution efforts are focused on gathering the information and providing a guideline as how to have a successful new faculty mentoring program. It is essential to validate the practicality and effectiveness of these processes. A majority of the handbooks and guidelines are well prepared and provide a clear vision of the process. However, the processes fall short of any follow up studies or documentation of the success and failure of these past practices. Hopefully, new faculty mentees will become the future mentors resulting in future generations of mentors. As a principal for any continues improvement process, ongoing feedback and process measurement metrics are required to indicate the degree that goal and objectives have been met. Without measuring the process improvement promoted by handbooks and guidelines, this information services for reference materials and not a living and working document. 


\section{Plans for Future Mentorship Processes}

Since the mentorship process is recognized as a critical success factor for many academic units, the key element is to develop the necessary infrastructure with the support of the leaders within the department or unit, then review and measure the effectiveness of this service. The bottom line for any effective mentoring program is that in order for programs to become successful, these programs must be continuously monitored and safeguards put in place to insure the success of the mentee faculty. Faculty members who are not performing to the required standards must be so advised early in their progress toward tenure. This notification should provide the individual with an opportunity to make the necessary corrections that will make them more competitive for promotion and tenure throughout their individual process. If they choose to ignore the guidance provided by their mentors (and by their administrative head who is responsible for conducting periodic performance assessments), at some point, they must be advised to look for work elsewhere. In many cases, this is the most fair and humane recommendation, since the long-term success of any professional - in any industry - is a blend of that person's individual interests and capabilities as they relate to the mission and expectations of the institutions. Our obligation, as mentors, is to advise the faculty on their progress along the way - both positively and negatively. We must not wait until the end of their fifth year to recommend a change, leaving the candidate no hope for creating the necessary body of work in the single year that remains before the tenure decision is made for them. Senior faculty members can facilitate success of new faculty members in a variety of ways, but an effective mentoring program within each academic unit is a proven methodology that is clearly within our ability to create and to sustain. It just takes our commitment to the process.

References

1. Center for faculty development. (2005). Retrieved January 9, 2007 from http://www.ecu.edu/csacad/facdev/index.cfm

2. Faculty welfare committee. (2005). Faculty mentoring report. Retrieved January 9, 2007 from http://www.ecu.edu/cs-acad/fsonline/customcf/committee/fw/mentoring.htm

3. Rigsby, C. A. (2004). Board of trustees remarks. Retrieved January 9, 2007 from http://www.ecu.edu/csacad/fsonline/customcf/bot/9_04Rigsby.doc

4. Rigsby, C. A. (2004). Board of trustees remarks. Retrieved January 9, 2007 from http://www.ecu.edu/csacad/fsonline/customcf/bot/9_04Rigsby.doc

5. Faculty welfare committee. (2005). Faculty mentoring report. Retrieved January 9, 2007 from http://www.ecu.edu/cs-acad/fsonline/customcf/committee/fw/mentoring.htm

6. Roberts, A. (1999, November). The origins of the term mentor. History of Education Society Bulletin, 64. 313329.

7. ECU faculty manual. (2006-2007). Retrieved January 12, 2007, from www.ecu.edu/fsonline/manual/facultymanual.cfm

8. Mentoring new faculty: Advice to department chairs. (1993). The American Physical Society. CSWP Gazette, $13(1)$.

9. ECU faculty manual. (2006-2007). Retrieved January 12, 2007, from www.ecu.edu/fsonline/manual/facultymanual.cfm

10. Mentoring new faculty: Advice to department chairs. (1993). The American Physical Society. CSWP Gazette, $13(1)$.

11. Mentoring new faculty: Advice to department chairs. (1993). The American Physical Society. CSWP Gazette, $13(1)$. 